\title{
Especialidades médicas e áreas de atuação
}

\author{
Harley E. A. Bicas
}

\begin{abstract}
"As entidades médicas nacionais reconhecem, a partir de agora, 48 especialidades médicas e 81 áreas de atuação. Este é o resultado do relatório final sobre a unificação das especialidades médicas, trabalho que durou seis anos e reuniu Associação Médica Brasileira (A.M.B.), Conselho Federal de Medicina (C.F.M) e Comissão Nacional de Residência Médica (C.N.R.M.) ". Assim começa uma nota sobre "Entidades unificam as especialidades médicas" saída à página 16 (última) do Jornal do CREMESP ( $\mathrm{n}^{\circ} 176$, abril de 2002). Ao conhecer as "especialidades" (48) encontrei $18 \mathrm{sem}$ as chamadas áreas de atuação (entre elas a Oftalmologia), enquanto Pediatria tinha 15, Ortopedia e Traumatologia 7. Foi o que me chamou a atenção. Na verdade, uma área de atuação, definida como "modalidade de organização do trabalho médico, exercida por profissionais capacitados para exercer ações médicas específicas, sendo derivada e relacionada com uma ou mais especialidades" podia
\end{abstract} estar subordinada a até três "especialidades"(como a Cirurgia Buco-Maxilo-Facial, cabente tanto a Cirurgia de Cabeça e Pescoço, como a Cirurgia Plástica e à Otorrinolaringologia; a Cirurgia Vídeo-Laparoscópica, enquadrável em Cirurgia Geral, Cirurgia do Aparelho Digestivo e Coloproctologia) de tal sorte que, em sua recontagem, elas são 59.

Certamente a lista exigiu trabalhos de composição e arranjos. É de se imaginar que representações das especialidades tenham sido mais (ou menos) atuantes, que deliberações hajam passado por acordos, que o provável cansaço da longa elaboração e a exigibilidade de uma resposta pressionassem por conveniências de que saísse uma proposta. Afinal, como diz o próprio texto, os estudos estenderam-se por seis anos. Saiu. Mas parece ter faltado uma revisão crítica de sua composição, uma ponderação sobre a logicidade das divisões, que numa especialidade é topográfica, em outra é sistêmica, às vezes nosológica ou, ainda, meramente baseada numa técnica ou método. Nada contra uma Ultra-sonografia em Ginecologia e Obstetrícia, mas é estranho que essa técnica (realmente, aí, tão desenvolvida) não tenha sua aplicação reconhecida em outras áreas (em Oftalmologia bem poderia ser chamada Ultrasonografia Ocular) e nem pertença, concomitantemente, à Radiologia e Diagnóstico por Imagem. Nada contra a que Ortopedia e Traumatologia tenha áreas de atuação em Cirurgia da Mão, do Pé, do Joelho, do Quadril, do Ombro, da Coluna, além da Ortopedia Pediátrica, não se concebendo, porém, que faltem à Oftalmologia, analogamente, as de Pálpebras, Córnea, Cristalino, Músculos e Retina (ou as de Anexos Oculares, de Segmento Anterior e de Segmento Posterior). Nada contra a Coloproctologia como especialidade; apenas a surpresa de que ela já não faça parte da de Cirurgia do Aparelho Digestivo (alguns preferem "sistema digestório") que, por sua vez, já não cabe em
Cirurgia Geral (ela própria tornada estranha sem as do Aparelho Digestivo, Torácica, Cardiovascular e outras). Por outro lado, em nossa especialidade, por que não a área de Cirurgia Refrativa? E com que razão deixar de nomear como atuação própria da Oftalmologia a Refratometria Ocular, ou Optometria, embora ela tenha sido insistentemente afirmada como tal? Por que não a de Ortóptica, cujos conceitos básicos de recuperação da visão binocular ainda persistem, após a caducidade de vários de seus antigos procedimentos, mas agora com técnicas pertinentes à ação do oftalmologista?

Nada contra as quinze áreas de atuação da Pediatria. Mas como explicar a ausência da de Psiquiatria da Infância e da Adolescência? Gozariam os psiquiatras de uma reserva especial de mercado de atuação? E por que, nelas, a de Infectologia Pediátrica, quando não aparece a vinculação analógica da de Infectologia Hospitalar a outra especialidade? E por que sim, também, a de Hematologia e Hemoterapia Pediátrica, quando a especialidade de Hematologia e Hemoterapia é dada como sem qualquer área de atuação? Mas se as faltas de paralelismo e reciprocidade são evidentes, o desprestígio maior fica mesmo com a Oftalmologia: pelo menos uma honrosa área de atuação poderíamos ter reconhecida, a de Oftalmologia Pediátrica, se ela fosse aglutinada pelo poder de diferenciação dos sistemas e órgãos da criança. Não o foi.

A um radiologista perguntei: em sua especialidade, a qual área de atuação ficará vinculada a investigação de uma lesão cerebral? À de Radiologia Intervencionista e Angiorradiologia, à de Ressonância Magnética, ou à de Neurorradiologia? Obviamente, qualquer resposta valeria, embora, pela mesma razão, nenhuma delas seja satisfatória. Por outro lado, é bem possível que ao se perguntar a um não médico (juiz? legislador? administrador?) a quem cabe o tratamento do câncer mamário, ou do retinoblastoma, ele indicará, na lista, o especialista em Cirurgia Geral (com Cirurgia Oncológica) ou Pediatria (com a área de Oncologia Pediátrica) ou, ainda, o especialista em Cancerologia (com uma dessas duas citadas áreas de atuação), mas certamente não a quem atue na Ginecologia e Obstetrícia, nem em Oftalmologia. Pois Mastologia, ou Oncologia Ocular não são áreas de atuação reconhecidas.

E por aí poderia seguir apontando outras impropriedades, incoerências, ilogicidades, assimetrias. A lista, afinal, é um atestado eloqüente e acabado de como não aplicar a teoria dos conjuntos a um problema desse tipo. Não faz jús ao esperado equilíbrio de raciocínio formal de um médico, menos ainda de suas representações oficiais.

É claro que um oftalmologista não deve ser o melhor crítico de uma (imaginável) tão árdua e longa disputa de subdivisões. Mas que a lista é, no mínimo, curiosa, isso ela é. Se fosse 
apenas por meros desequilíbrios de composição, acho que nem deveriam caber preocupações. Mas com a atual perspectiva de emergência de novas profissões e funções; com a esperada resistência dos convênios médicos a assumir diferenciações entre procedimentos oftalmológicos procurando, ao contrário, nivelá-los (e, claro, se possível todos pelo valor mais vil); e, finalmente, com a natural tendência à diversificação crescente de atuações dentro da Oftalmologia (já somos mais de dez mil e, amanhã, certamente mais, por simples crescimento "vegetativo") não convém que nossa especialidade se deixe banalizar. Não apenas comparativamente a outras, mas pelo refinamento e diversificação dos serviços que já presta à sociedade. Não se pode ter dúvidas de que logo essa lista estará influenciando desde a estrutura e valorização de Residências Médicas, ao reconhecimento diferenciado de procedimentos e ao próprio exercício da profissão.

A hipótese de que a Oftalmologia possa ter sido mais sábia do que outras especialidades e decidido manter-se una e in(sub)divisível para, com isso, ganhar maior poder de barganha com quem for doravante aplicar a lista e valer-se de suas conseqüências, não parece defensável. Será como ir contra a correnteza. Afinal, as distâncias entre um neuro-oftalmólogo e um cirurgião de retina, entre um contactólogo e um cirurgião de órbita, entre um que atue em visão subnormal e outro dedicado aos anexos oculares, são maiores do que as que separam áreas de atuação de certas especialidades médicas. E esse tipo de informação é devido ao usuário.

Inequivocamente, e sem entrar no âmago das conseqüências, já há muito se extinguiu a figura do médico "geral", o que atendia "tudo" com igual aptidão. A era da especialização também está passando, pelo próprio desenvolvimento da ciência, pela demanda do usuário, pela maciça oferta de oportunidades e serviços. Hoje, quem dirá que pratica toda a Oftalmologia? Claro que nos locais mais desprovidos alguém pode tentar fazê-lo mas, com toda a certeza, não o conseguirá com o nível de competência dos "superespecialistas" (aliás, já abundantes). Querendo ou não, certa ou erradamente, fomos compelidos à diversificação, às associações e agrupamentos, em que cada um tem sua "área de atuação".

Parece convir que elas sejam legalmente homologadas. Podemos precisar disso. Um projeto de lei recentemente apresentado pelo Ministério da Saúde regulamentando o exercício das especialidades médicas está em discussão em nossas entidades maiores antes de seu encaminhamento ao Congresso Nacional. Depois dessas consolidações, quem mudou, mudou; quem não mudou, tão cedo não muda mais...

\section{ABO ELETRÔNICO}

\section{A versão eletrônica dos Arquivos Brasileiros de Oftalmologia com textos completos está disponível em:}

- $\mathbf{A B O}$ - Arquivos Brasileiros de Oftalmologia http://www.abonet.com.br

- SciELO-Scientific Electronic Library Online http://www.scielo.org

- Free Medical Journals - http://www.freemedicaljournals.com 